\title{
СОВЕРШЕНСТВОВАНИЕ СТРУКТУРЫ АССОРТИМЕНТА И КАЧЕСТВА КОСМЕТИЧЕСКИХ ТОВАРОВ
}

\author{
Ахмеджсанова Ф.А. \\ к.т.н., дочент \\ Самаркандского института экономики и сервиса. \\ Узбекистан.
}

\section{IMPROVEMENT OF THE ASSORTMENT STRUCTURE AND QUALITY OF COSMETIC GOODS}

Аннотация. В статье приводятся данные исследования структуры ассортимента и качества косметических товаров. На основании проведенных исследований показаны пути совершенствования ассортимента и качества косметических товаров для потребителей с жарким, сухим климатом.

Annotation. The article presents the research data of the assortment structure and quality of cosmetic goods. On the research was provided improving ways of the cosmetic products range and quality for consumers who live on hot and dry climates.

Ключевые слова: ассортимент косметических товаров, структура ассортимента косметических товаров, лечебно-гигиеническая косметика, декоративная косметика, косметика класса «люкс», косметика класса «массмаркет», показатели качества косметических товаров, качество косметических товаров, совершенствование структуры ассортимента, совершенствование качества парфюмерных товаров.

Key words: assortment of cosmetic products, structure of the assortment of cosmetic products, medical and hygienic cosmetics, decorative cosmetics, luxury cosmetics, mass-market cosmetics, improvement of the assortment structure, improvement of the quality of perfumery products.

Слово «косметика» (от греч.»Cosmetik») означает искусство украшать. Современное понятие косметики значительно расширилось. В настоящее время косметикой называют комплекс товаров по уходу за волосами, полостью рта, кожей с целью предупреждения появления и устранения дефектов, предотвращения преждевременного старения кожи. Исходя, из этого ассортимент косметических товаров группируется на изделия лечебно-гигиенические и декоративные изделия. Ассортимент косметических товаров формируется, исходя из назначения, целевого назначения, вида, используемого основного сырья, объема или массы фасовки и вида упаковки изделия.[1] [4]

В последние десятилетия потребление косметических товаров во всем мире, в том числе и в нашей стране, возрастает. На нашем рынке появилось огромное количество новых товаров с новыми потребительскими свойствами. На сегодняшний день косметическую продукцию за рубежом производят более 500 фирм и предприятий, но более половины объема производства сконцентрировано в руках 10 крупнейших компаний: "L’Oreal” (Франция), "Procter\&Gamble” (США), Revlon (США), Florena, Londa, Wella, Schwarzkopf (Германия), “Oriflame” (Швеция), Lumene (Финляндия). Крупнейшим производителем парфюмерно-косметических товаров является США (около 1\3 общего объема). Для структуры ассортимента, производимого в мире парфюмернокосметических товаров, характерна значительная доля косметической продукции, причем около 65\% составляют средства для ухода за кожей. Это объясняется демографической ситуацией и преобладанием старших возрастных групп в структуре населения, пользующегося косметикой. Поэтому в последние годы производители затрачивают много средств, для производства косметических изделий, замедляющих старение. Большое внимание уделяется также, разработке гипоаллергенных косметических средств, т.к. увеличилось число людей, страдающих аллергией. Большую группу (второе место) среди косметических товаров составляют средства по уходу за волосами. В последние годы здесь увеличилась доля средств для укладки волос и придания им цвета.[2]

Насыщенность нашего рынка импортными товарами, высокие цены товаров известных западных фирм, низкое качество дешевых подделок вынудили отечественных производителей повысить конкурентоспособность своей продукции. Новые научно-исследовательские мероприятия, освоение новых технологий, художественное оформление, рекламные мероприятия, современный подход к товарной информации и др. исследования способствовали возрождению отечественной косметической промышленности, повышению спроса на отечественный товар.

На потребительские предпочтения на рынке косметики основное влияние оказывают цена, известность и авторитет фирмы, а так же реклама товара. Если раньше импортная косметика в Узбекистане воспринималась как качественная, то сейчас западное качество нужно доказывать, а высокие цены на импортные товары еще больше активизировало потребление и производство отечественной продукции. К сожалению, на отечественную продукцию с рекламой дела обстоят похуже. По телевидению мы видим в основном многообещающие рекламные ролики импортной продукции и под воздействием рекламы тратим не малые средства на их приобретение. Если 
бы отечественные производители так же широко использовали телевизионную рекламу, спрос на отечественную продукцию был бы выше.

Анализ рынка косметических товаров и особенностей ее потребления позволяет выделить на отечественном рынке следующие группы потребителей, объединенные по их требованиям к товару.

Высоко-обеспеченные потребители - требовательны к качеству, приобретают продукцию в фирменных магазинах, выбирая ее, прежде всего, по фирме-изготовителю, ее известности.

Среднеобеспеченные потребители - требовательны к качеству, проявляют интерес к публикациям, оценкам специалистов, приобретают продукцию в магазинах, выбирая по оптимальным ценам. Некоторые из них малотребовательны к качеству, покупают косметику по необходимости на рынках, киосках, улицах.

Малообеспеченные потребители - не требовательны к качеству, приобретают в основном косметику повседневного спроса - мыло, шампуни, зубные пасты.

В связи с этим косметические товары, по сложности, делятся на два класса: класс «люкс», в производстве которых используются натуральные и качественные компоненты, рассчитанные на покупателя с высоким уровнем дохода и класс «масс-маркет», в производстве которых используются синтетические компоненты, рассчитанные на покупателей с среднем и ниже среднего уровнями доходов.[3]

Коммерческая экспертиза парфюмерно-косметических товаров показала, что на долю класса «люкс» приходится 32\% ассортимента, а на долю класса «масс-маркет» - 68\% ассортимента косметических товаров.

Ассортимент косметических товаров, реализуемых в коммерческих структурах, включает в себя изделия для ухода за волосами, кожей, полостью рта, изделия для бритья и после бритья, производства компаний: «Procter\&Gamble», «Фратти-косметик», «Schwarzkopf», «Colgate-Palmolive», «Garner», ОАО Концерн «Калина», «Gillett», «Nivea» и др.

Нами, для изучения ассортимента косметических товаров, реализуемых в коммерческих структурах были анализированы такие показатели ассортимента, как назначение, целевое назначение, страна-изготовитель и виды косметических товаров, как основные факторы, формирующие ассортимент.

Ассортимент косметических товаров по целевому назначению включает в себя лечебно-гигиеническую и декоративную косметику. К лечебно-гигиенической относится косметика, предназначенная для ухода за волосами, кожей, косметические изделия для бритья и после бритья, по уходу за полостью рта, мыло и прочая гигиеническая косметика. Коммерческая экспертиза косметических товаров по целевому назначению показала, что 68\% реализуемой косметики приходится на лечебно-гигиеническую косметику, 32\% занимает декоративная косметика. (Рис.1)

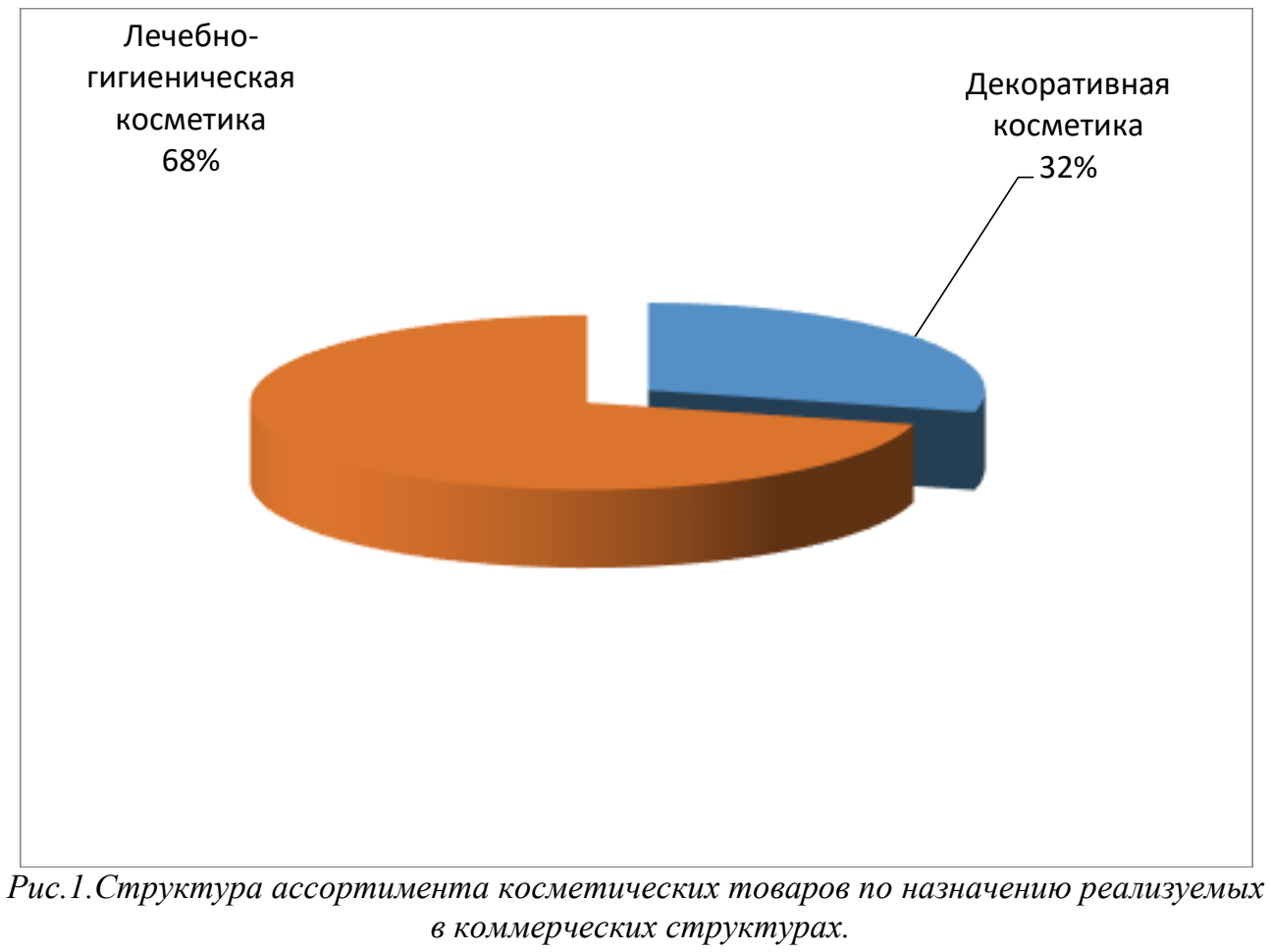

Анализ ассортимента лечебно-гигиенической косметики показал, что наибольший удельный вес - $30 \%$ занимают косметические изделия по уходу за волосами ; 20\% занимают изделия по уходу за кожей, это кремы для рук и лица, скрабы, молочко для умывания; по 11\% ассортимента приходится на мыло и косметические 
изделия для бритья и после бритья; наименьший удельный вес занимают изделия по уходу за полостью рта - $12 \%$; $16 \%$ ассортимента занимает прочая косметика, это такие изделия, как дезодоранты, антиперспиранты, лечебная косметика, продаваемая в аптечных сетях. (Рис.2)

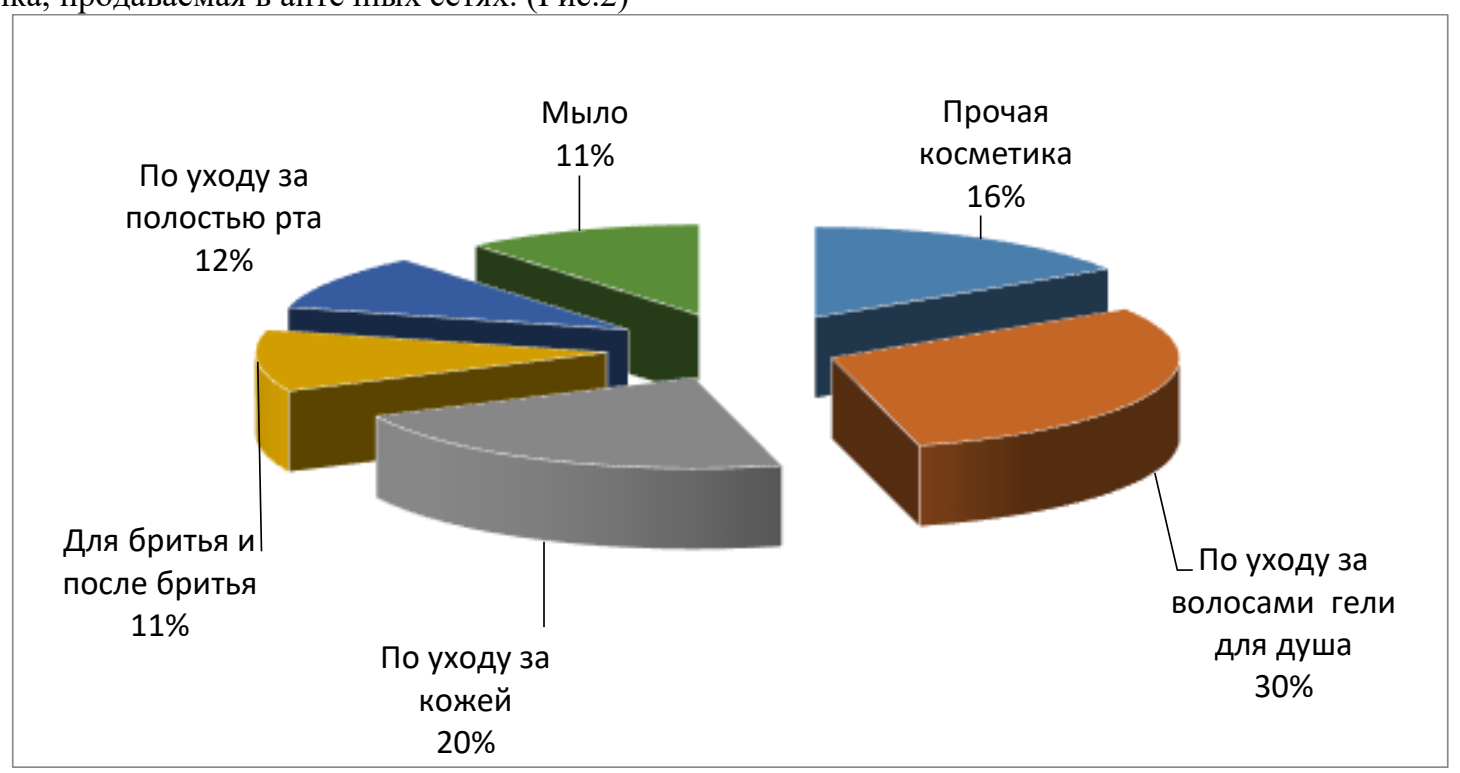

Рис.2. Доля лечебно-гигиенической косметики

по целевому назначению.

Ассортимент косметических товаров произведенных в Узбекистане в последние годы, из-за большого спроса на них намного расширился.

Наибольшее влияние на выбор потребителя оказывает известность бренда. Это, в свою очередь, напрямую связано с рекламными бюджетами косметических компаний. Всемирно известные транснациональные компании затрачивают миллиарды на поддержание известности своих торговых марок и формирование психоэмоциональной привязанности к ним со стороны потенциальных потребителей. Учитываются все факторы: от возраста до вероятного эмоционального состояния покупателя в момент посещения супермаркета или контакта с продавцом. Отсюда вытекает другая объемная статья затрат — социологические и прочие исследования поведенческих стереотипов покупателя.

Крупнейшим и старейшим в Узбекистане производителем косметических средств является АО «Лола атирупа», созданное в далеком 1942 году. С 2009 года предприятие полностью отказалось от производства парфюмерных изделий и сфокусировалось на производстве кремов, зубных паст и моющих средств. Такая перегруппировка позволила предприятию занять свою нишу на рынке и обеспечить свою устойчивость. Продукция АО «Лола атир упа» имеет высокий уровень локализации. Не менее 60\% сырья имеют местное происхождение. Модернизация оборудования, позволяет предприятию удерживать качество продукции на уровне, не уступающем зарубежным конкурентам. При этом ценовая политика предприятия весьма благосклонна к кошельку потребителя, что обеспечивает высокую популярность продукции предприятия в регионах республики.

На втором месте расположилось СП «Навои Бьюти», учрежденное совместно с южнокорейской DK Cosmetics. Первую партию косметики СП «Навои Бьюти» выпустило в 2010 году под брендом «Эстелль». Начиная с 2011 года продукция предприятия реализуется под брендом «La'Core», ориентированным на премиум-сегмент. В 2013 году компания осваивает выпуск продукции эконом-класса под брендом «Ве-Веаuty». Производственный цикл контролируется зарубежными специалистами — технологами из Кореи. В совокупности с импортируемым сырьем это обеспечивает необходимый уровень качества.

Из новичков на рынке косметической продукции, ставших достаточно заметными за короткий промежуток времени, можно также отметить узбекско-корейское СП «Global Cosmetics», созданное в 2013 году. Предприятие фокусируется на производстве косметических моющих средств для волос и тела не только для потребительского рынка, но и для сегмента рынка услуг красоты.

Наиболее острой проблемой сегодня является аллергическая реакция на косметические средства. По данным исследований косметические средства в основном декоративная косметика содержит множество химических соединений, которые вызывают аллергическую реакцию. Например, в состав некоторых в основном китайского производства карандашей для глаз, подводок и тушев для ресниц входят отходы переработки нефтепродуктов. А если учесть, что множества женщин и девушек почти каждый день пользуются этими средствами и на ночь не 
смывают - отсюда вытекают разные болезни глаз. Тени для глаз содержат множества консервантов и красителей, вызывающих разные реакции организма как коньюктивит и блефарит.

Из гигиенических косметических изделий шампуни и гели для душа требуют более внимательного изучения состава. Входящий в их состав парабены накапливаются в организме. Некоторые известные бренды почти исключили из состава своей продукции парабенов.

Пристального внимания требует, детская косметика и поэтому рекомендуется всегда покупать изделия известных производителей и внимательно изучать состав. Детские косметические средства не должны содержать красителей, искусственных ароматизаторов, консервантов. Следовать правилу, чем меньше состав, тем лучше.

Еще одна проблема требующего пристального внимания это нелегально привозимые косметические средства из ближнего зарубежья. Как правило, эти средства не имеют сертификатов качества. Если обратиться к цифрам то за 6 месяцев было зарегистрировано сотрудниками таможенного контроля 344 случаев нелегального привоза косметических средств на территорию Республики на сумму более 1 миллиарда сумов.

На основании проведенных исследований для совершенствования структуры ассортимента косметических товаров рекомендуем:

«Республиканскому центру исследований и контроля качества», а также органам СанитарноЭпидемиологического надзора:

- привлечь дополнительные инвестиции для оснащения аккредитованных лабораторий современным оборудованием для проведения физико-химических, микробиологических, токсико-гигиенических и других необходимых испытаний;

- уделить внимание подготовке квалифицированных специалистов в области проведения лабораторных испытаний;

- усилить работу по борьбе с фальсифицированной продукцией, пресечь продажу парфюмернокосметических товаров без гигиенического сертификата и сертификата соответствия.

\section{Производственным предприятиям:}

- на правах франчайзинга производить косметические товары по зарубежным технологиям, при этом наладить производство тех товаров, спрос на которые превышает предложение;

- уделить особое внимание разработкам новых технологий производства косметических товаров, с учетом жаркого сухого климата и интенсивной солнечной радиации;

- учитывая, что Узбекистан богат лечебными растениями и травами, которые могут послужить основным сырьем для производства косметических товаров, разработать комплекс лечебной косметики, объединенной в одну линию и назвать ее, например, «Магия трав» или «Восточная зеленая аптека».

- учитывая, что в нашей стране всегда уделяется большое внимание подрастающему поколению разработать комплекс лечебной косметики для детей и подростков;

- разработать комплекс декоративной и лечебной гипоаллергенной косметики.

Работникам коммерческих структур - периодически повышать свою квалификацию в области изучения потребительских свойств и ассортимента косметических товаров, а также в сфере навыков консультантапродавца.

\section{ИСПОЛЬЗОВАННАЯ ЛИТЕРАТУРА:}

1. Яковлева Л. А., Кутакова Г. С.. Товароведение парфюмерно-косметических товаров: Учебник для вузов. M:- 2015. -285c.

2. Тепло В.И. и др. Коммерческое товароведение. Москва: ИД "Дашков и К", 2000. - 241с.

3. Паршикова В.Н. «Парфюмерно-косметические товары» Красноярск : ГОУ ВПО "Красноярский гос. торгово-экономический ин-т", 2010. - 405 с.

4. Косолапова, Н.В. Товароведение парфюмерно-косметических товаров: учебное пособие / Н.В. Косолапов. М.: Издательский Центр «Академия», 2010. 164 с.

5. Вилкова С.А. Товароведение и экспертиза парфюмерно-косметических товаров.- М.: Деловая литература, 2005-240c. 